\title{
Universal Precautions in Preventing Central Venous Catheter Associated Blood Stream Infections. A Study at Tertiary Care Hospital of 'Central Line Bundles' in MICU
}

\author{
Dhanashree P. Inamdar ${ }^{1}$, Shripad Taklikar ${ }^{2 *}$ and Sujata Baveja ${ }^{2}$ \\ ${ }^{1}$ Department of Microbiology, Mamata Medical College and Hospital, \\ Khammam-507002, India \\ ${ }^{2}$ Department of Microbiology, LTMMC\& LTMGH, Sion, Mumbai-416416, \\ Maharashtra, India \\ *Corresponding author
}

\section{A B S T R A C T}

\begin{tabular}{|l|}
\hline Ke y w o r d s \\
Blood stream, \\
Central line \\
bundles, MICU, \\
CRLI
\end{tabular}

Keywords

\section{Introduction}

Central line associated blood stream infections (CLABSI) are serious cause of morbidity and mortality in patients admitted in ICUs (Intensive care unit) (Atilla et al., 2017). Precautions taken at every level while inserting central venous catheter plays a vital role in preventing morbidity in these patients. Although precautions play major role in
Central venous catheter insertion is a necessity while dealing with patients in MICU due to associated comorbid conditions. But following sterile barrier precautions while inserting and handling central line catheters is much more important as infectious complications take an upper hand if these "central line bundles" are not followed with great care. A prospective study was carried in a tertiary care hospital. The central line bundles while inserting the catheter with site and type was studied. Fifty (50) patients developed Catheter related local infection (CRLI) and seven (6) patients developed Central line associated blood stream infections (CLABSI). Female preponderance was seen in both local (52\%) and systemic (67\%) catheter infection. $96.4 \%$ of total patients had insertion at jugular site. Single lumen catheter was most commonly used (98\%). Decreased use of central line bundles like hand hygiene, cap and mask significantly $(\mathrm{p}<0.5)$ was noted. Central line bundles which includes insertion bundles and aftercare bundles plays a vital role in determining the infectious complications in MICU patients. E very attempt should be made to use barrier precautions to prevent further complications associated with central line because if not followed morbidity and mortality in the patients increases. 
antimicrobial agents before, during, or after catheterization; and frequency of intravenous (i.v.) administration set changes, remain unclear (Richet et al., 1990). Central line bundles which include care bundle during and after insertion of central venous catheters have to be borne in mind when treating patients in ICUs (Caroline O'Neil et al., 2016). Thus both central lines associated blood stream infections (CLABSI) and catheter related local infection (CRLI) in relation to Central line bundles was determined in the study.

The main aim of this study includes to determine site and type of central venous catheter commonly used in ICU. And to determine type of precautions used while inserting central venous catheter. Also to determine outcome in these patients.

\section{Materials and Methods}

A prospective study was carried out in the department of microbiology in collaboration with Medical Intensive Care Unit (MICU) in a tertiary care hospital.

Two hundred fifty consecutive adult patients on central venous catheter admitted in MICU constituted the study population.

\section{Inclusion criteria}

Adult patients on central venous catheters admitted in MICU and who developed systemic signs and symptoms of infections after 48 hours of admission.

\section{Exclusion criteria}

Patients with septicaemia due to causes other than central line.

Patients developing systemic signs and symptoms $<48 \mathrm{hrs}$ of admission.

\section{Study procedure}

All adult patients who met inclusion criteria were included in the study. Detailed clinical history of each patient was noted as per the clinical proforma with every day follow up to check vitals, local and systemic signs of sepsis along with precautions used during and after insertion of central venous catheter. Patient's clinical details including all risk factors, complete hemogram and serum electrolyte levels were also recorded

Relevant specimens were collected to establish CLABSI and CRLI which included central venous catheter (Issam et al., 2004) and blood samples. Other samples like urine, ET aspirate, sputum, pus was collected to rule out other infections.

Central line tip processing: The central venous catheter so collected was placed in sterile petri dish with the help of sterile forceps and then with sterile scalpel, the distal $5 \mathrm{~cm}$ portion was cut.

Semi quantitative extra luminal Maki's roll over plate method (Maki et al., 1977) and quantitative endoluminal catheter flush culture (Linares et al., 1985) were used for processing the central line tip.

\section{Diagnosis of central line related local and systemic infections}

\section{Central line related local infections (CRLI) was diagnosed as}

Any sign of local infection (induration, erythema, heat, pain, purulent drainage) and

Catheter tip colonization was defined as "Significant growth of a microorganism by $>15$ colony-forming units from the catheter tip by semiquantitative method or $>10^{3}$ by quantitative culture." 
Central Line Associated Blood Stream Infections (CLABSI) was diagnosed as

Recognized pathogen isolated from blood culture and pathogen not related to infection from another site (other than site of an intravascular device i.e. it should not have been isolated from urinary tract / respiratory tract / wound, etc).

\section{OR}

One of the following -

Fever (>38 C)

Chills

Hypotension

And any of the following:

Common skin contaminant isolated from two blood cultures drawn on separate occasions, and organism is not related to infection at another site.

Common skin contaminant isolated from blood culture from patient with intravascular access device and physician institutes appropriate antimicrobial therapy.

Positive antigen test on blood or organism is not related to infection at another site.

\section{Statistical analysis}

Results were noted down. Data was analysed statistically by using SPSS software for windows version 15.0, open epi software version 2.3, Microsoft excel 2007. Chi square analysis and Mid p test (wherever chi square cannot be applied i.e. failure to meet Cochrain's criteria) was applied for comparing cases (with infection) and control (without infection).

\section{Results and Discussion}

During the study period a total of 250 consecutive adult patients with central venous catheter were analysed. Of these fifty (50) patients developed Catheter related local infection (CRLI) and seven (6) patients developed Central line associated blood stream infections (CLABSI).

Female preponderance was seen in both local $(52 \%)$ and systemic $(67 \%)$ catheter infection (Table 1). Maximum patients having Local catheter infection were distributed among age group of 35-44 years (32\%), followed by 1524 years (20\%) and 25-34 years (20\%). While those with systemic catheter infections age group of 15-24 years (66.6\%) was common followed by $25-34$ years $(33.4 \%)$ as seen in Table 2. 96.4\% of total patients had insertion at jugular site followed by $3.6 \%$ of patients who had insertion at antecubital vein of the arm (Table 3). Single lumen catheter was most commonly used $(98 \%)$ followed by triple lumen catheter in $2 \%$ of patients (Table 4). Site of insertion was not found to be statistically significant with local catheter infection and systemic infection. All patients who developed systemic infection due to central line had jugular site of insertion (Table 5). Use of triple lumen catheter (p value $=0.048)$ increased the risk of local infection (CRLI) which was found to be statistically significant but none of the patients who developed CLABSI had triple lumen catheter (Table 6). Decreased use of alcoholic hand rub by healthcare workers lead to local infection in patients which was statistically significant ( $\mathrm{p}$ value $<0.005$ ).

Less use of barrier precautions like cap ( $p$ value $<0.005$ ) and mask ( $p$ value $<0.005$ ) by health care workers also contributed to local infections. In CLABSI All healthcare workers used gloves. However only one healthcare worker used cap and two healthcare workers wore mask. None of the healthcare workers used alcoholic rub or washed their hands before performing the procedure (Table 7). 
Intravascular catheter related blood stream infections are significant cause of illness in MICUs as they increase the morbidity and mortality of patients particularly those with associated comorbid conditions admitted in ICU's and additional medical cost.

\section{Association of catheter related infection with age and sex}

Female preponderance was observed in both CRLI (52\%) and CLABSI (67\%) in the present study. Although male gender was found to be a significant risk factor in a study conducted by Saxena and Bodh (2005) the present study did not show such significance.

Age was not a risk factor in the present study in comparison with a study conducted by (Pooja Gupta et al., 2011) on incidence of bacteremia associated with central venous catheter in patients on hemodialysis. But studies conducted by Powe et al., (1995) and Saxena and Bodh (2005) shows a significant association of catheter related infection with increasing age.

\section{Association of catheter related infection with the site of catheter used}

Jugular vein (96.4\%) was the most common site of central line insertion in the present study, significant statistical association was not seen with infection. One study done in 1990 observed a significant association of infection due to central venous catheter with the insertion site (jugular) which was conducted by (Richet et al., 1990).

Another study showed that femoral catheterization was linked with a higher incidence rate of infectious complications (19.8\% vs $4.5 \%$; $P, 001)$ when compared to other sites of catheter insertion by Merrer et al., (2001).

As in the present study we did not have femoral or subclavian site of catheter insertion which could be related to infectious consequences with subclavian or jugular site of insertion.

A study conducted by Nuria Fernandez Hidalgo et al., in 2006 on antibiotic-lock therapy for long-term intravascular catheterrelated bacteraemia: an open, non-comparative study showed that location of catheter in patients did not significantly increase the risk of infection ( $\mathrm{p}$ value=0.74). In another randomized control trial done by Jean-Jacques et al., (2008) in 2008 the risk of catheter colonization did not differ significantly between the femoral and jugular groups (incidence of 40.8 vs 35.7 per 1000 catheterdays; $P=.31$ ) which was comparable with the present study where we did not find any significant association of infection with jugular site of insertion.

Association of catheter related infection with the type of catheter used

Triple lumen catheter association with infection was significant risk factor (p value $=0.047$ ) in the present study.

In a study conducted by Ramanathan et al., (2011) in 2011, the incidence of catheterrelated infection was highest with triple lumen catheters $(39.8 \%, \mathrm{p}=0.002)$. (Marlene et al., 2010) observed an incidence of $19 \%$ among triple lumen and only $3 \%$ among single lumen subclavian catheters used for total parenteral nutrition. The present study was comparable with the above two studies. 
Table.1 Gender wise distribution among CRLI and CLABSI

\begin{tabular}{|l|l|l|l|l|l|l|l|}
\hline Gender & CRLI $(\mathbf{N}=\mathbf{5 0})$ & \multicolumn{2}{|l|}{ CLABSI (N=06) } & Total & \\
& $\begin{array}{l}\text { No. of } \\
\text { cases }\end{array}$ & $\begin{array}{l}\text { Percentage } \\
(\%)\end{array}$ & $\begin{array}{l}\text { No. of } \\
\text { cases }\end{array}$ & $\begin{array}{l}\text { Percentage } \\
(\%)\end{array}$ & $\begin{array}{l}\text { No. of } \\
\text { cases }\end{array}$ & Percentage \\
\hline Male & 24 & $48 \%$ & 02 & $33 \%$ & 27 & $48.2 \%$ \\
\hline Female & 26 & $52 \%$ & 04 & $67 \%$ & 29 & $51.8 \%$ \\
\hline Total & $\mathbf{5 0}$ & $100 \%$ & 06 & $100 \%$ & 56 & $100 \%$ \\
\hline
\end{tabular}

Table.2 Age wise distribution among CRLI and CLABSI

\begin{tabular}{|c|c|c|c|c|}
\hline \multirow[t]{2}{*}{ Age distribution } & \multicolumn{2}{|c|}{ CRLI (N=50) } & \multicolumn{2}{|c|}{ CLABSI (N=06) } \\
\hline & No. of cases & Percentage (\%) & No. of cases & Percentage $(\%)$ \\
\hline $15-24$ & 10 & $20 \%$ & 04 & $66.6 \%$ \\
\hline $25-34$ & 10 & $20 \%$ & 02 & $33.4 \%$ \\
\hline $35-44$ & 16 & $32 \%$ & 00 & 00 \\
\hline $45-54$ & 09 & $18 \%$ & - & - \\
\hline $55-64$ & 04 & $8 \%$ & - & - \\
\hline$>65$ & 01 & $2 \%$ & - & - \\
\hline Total & 50 & $100 \%$ & 06 & $100 \%$ \\
\hline
\end{tabular}

Table.3 Distribution of patients as per site of insertion of central venous catheter $(n=250)$

\begin{tabular}{|l|l|l|}
\hline Site & No. of patients & Percentage (\%) \\
\hline Femoral & 0 & $0 \%$ \\
\hline Jugular & 241 & $96.4 \%$ \\
\hline Antecubital & 9 & $3.6 \%$ \\
\hline Subclavian & 0 & $0 \%$ \\
\hline Total & $\mathbf{2 5 0}$ & $\mathbf{1 0 0 \%}$ \\
\hline
\end{tabular}

Table.4 Distribution of patients as per type of catheter used $(n=250)$

\begin{tabular}{|l|}
\hline Type \\
\hline Single lumen \\
\hline Triple lumen \\
\hline Total \\
\hline
\end{tabular}

\begin{tabular}{|l|l|}
\hline No. of patients & Percentage (\%) \\
\hline 246 & $98.4 \%$ \\
\hline 4 & $2 \%$ \\
\hline $\mathbf{2 5 0}$ & $\mathbf{1 0 0 \%}$ \\
\hline
\end{tabular}

Table.5 Association of CRLI and CLABSI with site of insertion $(n=250)$

\begin{tabular}{|c|c|c|c|c|}
\hline Site $(n=250)$ & Control $(n=194)$ & CRLI $(n=50)$ & p valve & $\operatorname{CLABSI}(n=6)$ \\
\hline Jugular & $185(95.3 \%)$ & $49(98 \%)$ & 2.35 & $6(100 \%)$ \\
\hline antecubital & $9(4.7 \%)$ & $1(2 \%)$ & 0.17 & ------------ \\
\hline subclavian & -------- & nil & ---------------- & ------------ \\
\hline femoral & --------------- & nil & -------------- & -------------- \\
\hline
\end{tabular}


Table.6 Association of CRLI and CVCBSI with the type of catheter used ( $\mathrm{n}=250)$

\begin{tabular}{|l|l|l|l|l|}
\hline TYPE $(\mathbf{n = 2 5 0})$ & Control $(\mathbf{n = 1 9 4})$ & CRLI $(\mathbf{n = 5 0})$ & p valve & CLABSI(n=6) \\
\hline Single lumen & $190(97.9 \%)$ & $47(94 \%)$ & 0.20 & $6(100 \%)$ \\
\hline Triple lumen & $4(2.1 \%)$ & $3(6 \%)$ & $\mathbf{0 . 0 4 7}$ & ---------- \\
\hline
\end{tabular}

Table.7 Association of CRLI and CLABSI with barrier precautions used $(\mathrm{n}=250)$

\begin{tabular}{|c|c|c|c|c|c|c|c|}
\hline $\begin{array}{l}\text { Precautions } \\
\text { used }\end{array}$ & $\begin{array}{l}\text { CRLI } \\
(\mathbf{n}=50) \%\end{array}$ & $\begin{array}{l}\text { Odds } \\
\text { Ratio }\end{array}$ & $\begin{array}{l}95 \% \\
\text { interval }\end{array}$ & $\begin{array}{l}\text { Confidence } \\
\text { wer upper }\end{array}$ & $\begin{array}{l}\text { Z } \\
\text { statistics }\end{array}$ & $\begin{array}{l}\text { Level of } \\
\text { significance }\end{array}$ & CLABSI \\
\hline $\begin{array}{l}\text { Alcoholic } \\
\text { rub }\end{array}$ & $3(6 \%)$ & 0.1131 & 0.0339 & 0.3767 & 3.55 & $\begin{array}{l}(\mathbf{P}<0.05) \\
\text { Significant }\end{array}$ & ------ \\
\hline Soap & $10(20 \%)$ & 0.6651 & 0.3106 & 1.4243 & 1.050 & $\begin{array}{l}(\mathrm{P}>0.05) \\
\text { Not significant }\end{array}$ & -------- \\
\hline fingernails & $2(4 \%)$ & 4.000 & 0.5493 & 29.1266 & 1.369 & $\begin{array}{l}(\mathrm{P}>0.05) \\
\text { Not significant }\end{array}$ & ------- \\
\hline Gloves & $50(100 \%)$ & 0.2596 & 0.0051 & 13.2347 & 0.67 & $\begin{array}{l}(\mathrm{P}>0.05) \\
\text { Not significant }\end{array}$ & $6(100 \%)$ \\
\hline Caps & $3(6 \%)$ & 0.1743 & 0.0520 & 0.5843 & 2.831 & $\begin{array}{l}(\mathbf{P}<0.05) \\
\text { Significant }\end{array}$ & $1(16 \%)$ \\
\hline Masks & $8(16 \%)$ & 0.1395 & 0.0622 & 0.3128 & 4.779 & $\begin{array}{l}\mathbf{P}<0.05 \\
\text { significant }\end{array}$ & $2(33 \%)$ \\
\hline Gown & $2(4 \%)$ & 0.7667 & 0.1625 & 3.6161 & 0.336 & $\begin{array}{l}\mathrm{P}>0.05 \\
\text { Not significant }\end{array}$ & ----------- \\
\hline
\end{tabular}

In the present study infection was significantly associated when comparison was made between triple lumen catheters vs single lumen catheters $(75 \%$ vs $25 \%)$ for local catheter infection. Similar observations were made by (Mathias et al., 2004).

They compared infections during use of triple lumen with single lumen catheters (12.8\% vs. $0 \%$ ) for administering parenteral nutrition. Higher rates of infection in triple lumen catheters were attributed to frequent handling of such catheters by health-care providers and the possibility of contamination during such procedures.

Another study has also demonstrated an increase in BSI rates in patients who used multiple-lumen catheters (Moretti et al., 2005).

\section{Central line bundles}

\section{Hand hygiene}

Hand hygiene remains a key measure in reducing nosocomial infections in the health care setting.

Health care workers' hands are frequently contaminated by organisms acquired from colonized patients and their immediate environment, and these may be readily transmitted to other patients in the absence of adequate hand hygiene (Zhuolin et al., 2010).

Alcoholic hand rub was not used in majority of opportunities observed in the present study and contributed to significant infection. Every healthcare worker used gloves while inserting central line catheter but performing handwash 
or using an alcoholic hand rub was very little. Although gloves provide skin barrier contributing to infection, still use of either an alcohol-based waterless product or antiseptic soap and water is recommended prior to central line placement (Zhuolin et al., 2010).

\section{Personal protective equipments}

Protective sterile barriers and clothing help minimize the risk of contamination and colonization of the catheter and insertion site during CVC placement.

The benefit of maximal sterile barrier precautions (MSBPs), consisting of a surgical gown, sterile gloves, mask, cap, and a large sheet drape, in limiting CLABSI was initially borne out in a single-center randomized, controlled trial involving cancer outpatients receiving chemotherapy. In the above study CLABSI rates were 6-fold higher in the control group which used only sterile gloves and a small drape (standard sterile barrier precautions, SSBP) during catheter placement when compared to the intervention group assigned to use MSBP (0.5 versus 0.08 infections/1000 catheter-days for the control versus the intervention group, respectively; $P$ $=0.02)(\operatorname{Raad}$ et al., 1994).

In the present study only $3(6 \%)$ healthcare workers used cap and 8 (16\%)used mask, thereby increasing risk of local infections and which was also found to be statistically significant ( $\mathrm{p}<0.05)$, whereas $16 \%$ used cap and $33 \%$ used mask which contributed to systemic infections due to central venous catheter in MICU.

\section{Outcome}

In the present study all six patients who developed CLABSI expired which is consistent with the findings of a study done by Pawar et al., (2004).
CRLI which is a Local infection caused due to central venous catheterization did not show relation with the outcome as $p$ value was statistically insignificant ( $>00.05)$. Further studies need to be done in this area as no studies are available relating local infection with bad outcome in the patients. One such reason is removal of catheter when local infection is suspected and antibiotic therapy to decrease the further complication.

To conclude, central line bundles play a vital role in preventing infectious complications in patients with central line catheters. Site of insertion and type of the catheter to be chosen should also be kept in mind as they do contribute to increase the morbidity and mortality in patients particularly in ICUs.

\section{References}

Atilla A, Doğanay Z, Kefeli Çelik H, Demirăg MD, S Kiliç S. Central line-associated blood stream infections: characteristics and risk factors for mortality over a 5.5-year period. Turk J Med Sci. 2017 Apr 18; 47(2): 646-652.

Caroline O'Neil et al., A Central Line Care Maintenance Bundle for the Prevention of Catheter-Associated Bloodstream Infection in Non-ICU Settings. Infect Control Hosp Epidemiol. 2016 June; 37(6): 692-698.

Charalambos Charalambous, BSc; Sandra M. Swoboda, RN, MSN; James Dick, PhD; et al., Risk Factors and Clinical Impact of Central Line Infections in the Surgical Intensive Care Unit. Arch Surg. 1998; 133(11):1241-1246.

Gupta P, Set R, Mehta K, Shastri J. Incidence of Bacteremia Associated With Central Venous Catheter In Patients on Hemodialysis Int $J$ Pharm Pharm 2011; 3(3):135-138.

Issam R, Hend AH, Badie A, Chatzinikolaou I, Marcella MJ, and Tarrand J. Differential Time to Positivity: A Useful Method for Diagnosing Catheter-Related Bloodstream Infections. Annals of Internal Medicine 2004; 140:19-22.

Jean-Jacques $\mathrm{P}$, Marina $\mathrm{T}$, Bruno $\mathrm{M}$ et al., Femoral vs Jugular Venous Catheterization and Risk of Nosocomial Events in Adults Requiring Acute Renal Replacement Therapy 
A Randomized Controlled Trial. Journal of American Medical Association 2008; 299(20):2413-2422.

Linares J, Antonio S, Javier G, José 1, Rogelio M. Pathogenesis of Catheter Sepsis: a Prospective Study with Quantitative and Semi quantitative Cultures of Catheter Hub and Segments Journal of Clinical Microbiology 1985: 21(3); 357-360.

Maki, D. G., C. E. Weise, and H. W. Sarafin. A semi quantitative culture method for identifying intravenous-catheter-related infection N. Engl. J. Med. 1977. 296:13051309.

Marlene R, Michael G, Mitchell J, Gayane Y, Charles W, Michele $\mathrm{M}$ et al., Decreasing PICU Catheter-Associated Bloodstream Infections: NACHRI's Quality Transformation Efforts. Journal of American Academy of Pediatrics 2010; 125; 206-213.

Mathias ZR, Martin R, Trame R, DPhil, and Bernhard Walder. Colonization and Bloodstream Infection with Single- Versus Multi-Lumen Central Venous Catheters: A Quantitative Systematic Review. Anesth Analg 2004; 99:177-82.

Merrer J, Jonghe B, Golliot F, Lefrant J, R Brigitte, P Rigaud. Complications of Femoral and Subclavian Venous Catheterization in Critically Ill Patients A Randomized Controlled Trial JAMA 2001; 286(6):700-707.

Moretti EW, Ofstead CL, Kristy RM et al., Impact of central venous catheter type and methods on catheter-related colonization an bacteremia. $J$ Hosp Infection 2005; 61:139-45.

Nuria F, Benito A, Raquel C, Isabel R, Ana M, Dolors $\mathrm{R}$ et al., Antibiotic-lock therapy for long-term intravascular catheter-related bacteraemia: results of an open, non- comparative study. Journal of Antimicrobial Chemotherapy 2006; 57:1172-1180.

Pawar M, Mehta Y, Kapoor K, Sharma J, Gupta A, and Trehan N Central Venous CatheterRelated Blood Stream Infections: Incidence, Risk Factors, Outcome, and Associated Pathogens. Journal of Cardiothoracic and Vascular Anesthesia 2004; 18(3): 304-308

Powe, N.R., Jaar, B., Furth, S.L., Briggs, W. 1995. Septicemia in dialysis patients: incidence, Risk factors and Prognosis. Kidney International. 55: 1081- 1091.

Raad II, Hohn DC, Gilbreath BJ, et al., Prevention of central venous catheter-related infections by using maximal sterile barrier precautions during insertion. Infect Control Hosp Epidemiol. 1994; 15(4 Pt 1): 231-238.

Ramanathan P, Jatan BS, Muralidhar VD, Chiranjay M, Sudha V. Intravascular CatheterRelated Infections In An Indian Tertiary Care Hospital. J Infect Dev Ctries 2011; 5(6):452458.

Richet H, Hubert B, Nitemberg G, Andremont A, Buu hoi A, Ourbak $\mathrm{P}$ et al., Prospective multicenter study of vascular-catheter-related complications and risk factors for positive central-catheter cultures in intensive care unit patients. Journal of Clinical Microbiology 1990; 28(11); 2520-2525.

Saxena, A.K., and Bodh, R.P. 2005. Hemodialysis Catheter related Bloodstream Infections: current treatment options and strategies for prevention. Swiss Med Wkly. 135: 127-138.

Zhuolin H, Stephen YL, Marschall J. Current strategies for the prevention and management of central line-associated bloodstream infections. Infection and Drug Resistance 2010: 3 147-163.

\section{How to cite this article:}

Dhanashree P. Inamdar, Shripad Taklikar and Sujata Baveja. 2018. Universal Precautions in Preventing Central Venous Catheter Associated Blood Stream Infections. A Study at Tertiary Care Hospital of 'Central Line Bundles' in MICU. Int.J.Curr.Microbiol.App.Sci. 7(01): 24842491. doi: https://doi.org/10.20546/ijcmas.2018.701.298 